\title{
Considering, planning, and realizing migration in early adulthood. The influence of life-course events and perceived opportunities on leaving the city in Germany
}

\author{
Stefanie A. Kley • Clara H. Mulder
}

Received: 12 January 2009/Accepted: 17 July 2009/Published online: 5 November 2009

(C) The Author(s) 2009. This article is published with open access at Springerlink.com

\begin{abstract}
Despite the common acknowledgement that migration is a process, the vast majority of empirical migration studies focus on actual moves without paying attention to the stages preceding them. We use an analytical framework in which the migration process is subdivided into a phase of decision-making, consisting of considering and planning the move, and another phase of realizing it. We investigate which part both life-course events and perceived opportunities play in each stage of the migration process for moves out of the city among young adults aged 18-29 years. The data come from a representative survey in two German cities (Magdeburg and Freiburg) and were gathered via a two-wave design in 2006 and 2007. Results from a generalized ordered logistic regression analysis of not considering, considering, or planning migration reveal that perceived opportunities and life-course events are important predictors of considering and planning migration, whereas beginning tertiary education and beginning a job are particularly important to entering the planning stage. Results from a binomial logistic regression of moving versus staying show that resources are particularly important for putting the decision in favor of migration into action.
\end{abstract}

Keywords Migration - Residential mobility · Decision-making and behaviour · Life-course $\cdot$ Early adulthood

\section{Introduction}

There is a considerable body of literature stating that migration is often linked to certain events in the life course, for example enrolling in higher education, starting in a new job, or

\footnotetext{
S. A. Kley $(\bowtie)$

Fakultät Wirtschafts- und Sozialwissenschaften, Fachbereich Sozialwissenschaften, Universität Hamburg, Allende-Platz 1, 20146 Hamburg, Germany

e-mail: stefanie.kley@uni-hamburg.de

C. H. Mulder

Faculty of Social and Behavioural Sciences, University of Amsterdam, Nieuwe Prinsengracht 130, 1018 VZ Amsterdam, The Netherlands
} 
starting to live with a partner (Wagner 1989; Mulder 1993; Mulder and Hooimeijer 1999; Clark and Huang 2003; Geist and McManus 2008). Furthermore, opportunity differentials between the place of residence and a possible destination have been considered to play a major part since the very beginning of migration research (e.g. Sjaastad 1962).

In migration research the idea is now common that migration is a process rather than just an event (e.g. Brown and Moore 1970). Any kind of voluntary migration, whether it means leaving a city, a region, or a country, starts with considering moving or having a desire to move. This thinking about moving might or might not develop into a more concrete intention or plan to move. A period follows in which the potential migrant searches for housing or possibly for a job, and in which individual or external circumstances may facilitate or constrain the realization of the move. After a given period of time we might or might not observe the act of moving.

Despite the common acknowledgement that migration is a process, the vast majority of empirical migration studies focus on actual moves without paying attention to the preceding stages. This is understandable because the data needed to take the various stages into account are scarce. But it is also unfortunate, because it implies that various ideas about which factors play a part in which stage of the migration process have hardly been tested empirically. Empirical studies that do pay attention to the process of migration are mostly based on longitudinal investigations of wishes or intentions to move and subsequent actual moving behavior (Rossi 1980; Duncan and Newman 1976; McHugh 1984; Landale and Guest 1985; Sly and Wrigley 1985/86; Fuller et al. 1986; Gardner et al. 1985/86; Simmons 1985/86; De Jong et al. 1986; Lu 1998; Kan 1999; Fang 2006; De Groot et al. 2007). These studies indeed find that several determinants play different parts in the decision to move and the realization of this decision.

The aim of this paper is to provide more insight into what part both life-course events and perceived opportunities play in each stage of the migration process. We apply an analytical framework in which the migration process is observed in a more precise way than in most previous work. We split the migration process into a phase of decisionmaking, whereby we distinguish between considering and planning to move, and another phase of realizing the move (cf. Kalter 1997). We address three research questions: (1) in which stage of the migration process do life-course events exert their influence on migration? (2) In which stage of the migration process are perceived opportunities relevant? And (3) are perceived opportunities still influential if life-course events are considered?

Our analysis focuses on migration out of two towns in Germany with different opportunity structures, and on the phase of early adulthood. Many life-course events, and therefore also a major share of migration processes, are concentrated in this life-course phase. The data were derived from a survey in two middle-sized cities, Magdeburg in Eastern Germany and Freiburg in Western Germany, and were gathered via a two-wave design in 2006 and 2007. From this survey, we selected respondents aged 18-29 years to represent the life-course phase of early adulthood. We refer to migration as moving beyond the city boundary. In most cases, these are long-distance moves; of those who left the city, 93.3\% moved more than $50 \mathrm{~km}$. Considering and planning leaving the city was analyzed via generalized ordered logistic regression. Realizing the migration decision was analyzed via a binomial logistic regression of moving versus staying, while taking the earlier stages of migration decision-making into account. Using the same predictors in each model, it is shown in which phase in the migration process perceived opportunities and life-course events-among other predictors-exert their influence. 


\section{Theory, previous research, and hypotheses}

\subsection{Stages in the migration process}

The work on residential mobility within cities and metropolitan areas was the first to focus on the process of relocation decision-making and behavior (for an overview see Mulder 1996). Rossi (1980 [1955]) analyzed different stages of the relocation process, using data for the metropolitan area of Philadelphia. He found that the desire to relocate was widespread, and that 'complaints' about the dwelling and the housing environment explained a great deal of this desire. Information about the intention to move was gathered by asking the respondents whether they expected to live in the same dwelling for another 10 months. One key finding for our research question was that the intention to move was only influenced by the 'complaints' if people had a desire to move. Rossi concluded that the desire to move is a necessary but not a sufficient condition for intending to move. As expected, the intention to move was a good predictor of realizing it. These findings support the conceptualization of a three-stage model of migration decision-making in which the stages are the desire to move, the concrete intention, and the actual move.

A different conceptualization of intra-urban migration also distinguishes three stages. In a first phase, stress at the place of residence leads to the decision to search for a new dwelling; the second phase comprises a search process for housing and other opportunities that lead to a decision either in favor of or against relocation; and the third phase is the act of moving (Brown and Moore 1970). Still slightly differently, Speare et al. (1975) distinguished a stage in which people develop a desire to move mostly due to dissatisfaction, a stage in which they weigh the costs and benefits of various alternative locations and decide whether or not to move, and a stage in which they actually move.

Empirical applications of three-stage models of migration are rare, most likely because they would require a complicated research design, and data measuring three stages are hardly available (exceptions are Speare et al. 1975; Kalter 1997). Yet there is modest but growing number of empirical studies in which two stages are distinguished, usually by means of a longitudinal investigation of intentions or expectations to move and subsequent actual moving behavior (Speare 1974; Duncan and Newman 1976; McHugh 1984; Landale and Guest 1985; Sly and Wrigley 1985/86; Fuller et al. 1985/86; Gardner et al. 1985/86; De Jong et al. 1985/86; Kalter 1997; Lu 1998; Kan 1999; Fang 2006; De Groot et al. 2007).

The operationalization of residential mobility or migration decision-making often differs considerably across the studies (cf. Simmons 1985/86). Mobility intentions are mostly measured either as expectations to move (e.g. Duncan and Newman 1976; McHugh 1984; De Jong et al. 1985/86) or as mobility plans (Kalter 1997; Clark and Ledwith 2006; Andersen 2008). Rarely were respondents asked about their thoughts or desires to relocate (e.g. Speare 1974; Landale and Guest 1985; Kalter 1997). Furthermore, the time horizon and the type of move differ considerably between the studies. There is evidence that expectations about relocation are more reliable if they are reported with respect to a relatively short period (e.g. 8 months; McHugh 1984) than with respect to the next couple of years (Duncan and Newman 1976). Moreover, the type of move measured includes mobility between neighborhoods in one metropolitan area (e.g. Rossi 1980; Landale and Guest 1985), leaving the village in a rural setting for at least 1 or 2 weeks (Fuller et al. 1985/86; Sly and Wrigley 1985/86), and leaving the city (Kalter 1997). This makes a comparison of the results difficult. Nevertheless, we shall summarize some central findings that are relevant to our research question. 
The anticipation of such life-course events as the beginning of a new job or retirement has been shown to influence mobility intentions (Kalter 1997; Kan 1999). Considering relocation or having a desire to move was found to be strongly influenced by the satisfaction with housing, neighborhood or community issues (Rossi 1980; Speare 1974; Landale and Guest 1985) or the perception that opportunities might be better elsewhere (Kalter 1997). Satisfaction with local conditions was also found to influence planning relocation or having the intention to move, but only marginally (Rossi 1980; Fang 2006; Lu 1998, 1999; Clark and Ledwith 2006). ${ }^{1}$

Realizing the move has been found to be at least moderately influenced by the intention to relocate (Rossi 1980; McHugh 1984; Landale and Guest 1985; De Jong et al. 1985/86; Fuller et al. 1985/86; Kan 1999). If this was not found to be the case, the reasons might lie in a wide or not precisely verbalized time horizon (Duncan and Newman 1976; cf. McHugh 1984) or in specific migration settings, such as short-time repeat migration (Sly and Wrigley 1985/86). There are indications that life-course events influence the realization of intentions to move in a different way than their association with the likelihood of moving regardless of intentions would suggest: for those with an expectation to move, job change appeared to have a negative effect on subsequent moving behavior (Kan 1999). In these cases an unpredictable job offer apparently impeded the execution of mobility plans. Interestingly, actual migration behavior was often found to be hardly influenced by the satisfaction with local conditions or perceived opportunity differentials (Landale and Guest 1985; De Jong et al. 1985/86; Sly and Wrigley 1985/86; Fuller et al. 1985/86; Kalter 1997; Clark 2003; Fang 2006). With the advancement of the process of relocation or migration decision-making, the satisfaction with local conditions seems to lose its influence.

We apply a three-phase model of migration, consisting of considering migration, planning it, and finally realizing it (Kalter 1997). The idea of distinguishing between considering and planning is supported by results from psychology (Heckhausen and Gollwitzer 1987; Heckhausen 1991; Gollwitzer 1996). While people are likely to consider lots of aspects and drop thoughts again without necessarily developing the intention for a particular behavior if they are in an early phase of decision-making, they will stick to their intention once the decision in favor of a certain behavior has been made. When deciding to act in a certain way, people are 'crossing the Rubicon' and are striving to make their goals come true. Therefore, the step from considering to planning the move indicates that the decision is in favor of moving.

The first stage of considering migration is hypothesized to be mainly the result of perceived opportunity differentials between the place of residence and alternative places. We prefer perceived opportunity differentials over satisfaction with local conditions because a rational decision about moving or staying is only plausible if alternatives to living at the current place of residence are perceived (Speare 1971; Kalter 1997). The perception of opportunity differentials and accompanying thoughts about moving might arise with changes in one's own life-course or in the life-course of significant others, like the partner. Certain life-course events disarrange the requirements at the place of residence. The birth of a child, for example, brings daycare facilities or aspects of environmental

\footnotetext{
1 In contrast to these results, Andersen (2008) found dissatisfaction with the neighborhood to have a strong influence on planning to leave the neighborhood. The reason for this different finding might be found in the long time horizon of planning: to move within 2 years. This might measure relatively vague thoughts rather than concrete plans. Moreover, the study was restricted to deprived areas, in which dissatisfaction with neighborhood conditions might be particularly influential.
} 
safety into mind. Other events, such as school completion, lead to the severance of social ties at the place of residence.

The second step, planning migration, is hypothesized to be mainly the result of the anticipation of life-course events that establish new contacts with a possible destination. This could be, for instance, a job offer.

The realization of the move is hypothesized to be mainly the result of planning it. Perceived opportunity differentials and anticipated life-course events should not have an influence on this last step of the migration process; we expect them only to have an influence on the earlier stages of migration decision-making. Furthermore, unforeseen constraints and facilitators, such as financial, social, and psychological resources, might have an influence on realizing migration, because they hamper or support putting intentions into action (Moore 1986; Massey and Espinosa 1997; Lu 1998, 1999; Palloni et al. 2001; Fang 2006).

\subsection{Migration in early adulthood}

Life-course events are of great importance to migration (Mulder and Hooimeijer 1999). Partly because the life course is framed by institutions, many life-course events are to a great extent typical of certain life-course phases and age spans (cf. Mayer 2004). In Germany as in other North-Western European countries, life-course events which are typical of the transition to adulthood mainly take place before the age of 30 (Kley and Huinink 2006; cf. Mandic 2008). Life-course events that have been found to influence migration in early adulthood are starting vocational training or university, beginning a (first) job, and union formation in the form of cohabitation or marriage (Wagner 1989; Mulder 1993). Furthermore there is evidence that plans for starting a family and having a child tend to trigger leaving the city (Huinink and Wagner 1989; Kulu 2008). Obviously, leaving the parental home also affects migration, but in different ways depending on its link to other events in the life course. If it is for starting university education, leaving home frequently leads young people over the city boundaries, while moving together with a partner does so less frequently (Wagner 1989; Mulder 1993; Kley and Huinink 2006). Because of this link with other life-course events, and because it implies a move by definition, leaving the parental home should not be thought of as an independent life-course event in our analysis. We do, however, account for whether the respondent lives in the parental home before a potential move.

Enrolment in post-secondary education is frequently connected with long-distance moves of young adults, especially those below 25 years of age (Wagner 1989; Mulder 1993). Respondents between 25 and 30 years old reported work and marriage or cohabitation as the most important motives for long-distance moves (Mulder 1993). Starting a tertiary education and starting a job are both events that might lead to the establishment of new social ties at a possible destination. We therefore expect these to have a greater influence on planning than on considering migration.

Marriage and cohabitation are among the most important motives for long-distance moves in early adulthood (Wagner 1989; Mulder 1993), especially for women (Mulder and Wagner 1993). So, union formation explains a great deal of the higher risk of moving for singles compared to couples (Mulder and Wagner 1993). Kulu (2008) found that the expectancy of a first birth enhances the likelihood of moving not only for couples but also for single persons and concludes that these moves are related to union formation. Any change in marital status enhances the risk of moving significantly (Clark and Huang 2003; Li 2004; Clark and Ledwith 2006) and naturally this also holds for divorce and separation. 
But because divorce only gains relevance at ages over 30 (Geist and McManus 2008) and probably also because many separations take place rather unexpectedly, we do not expect to observe many anticipated separations in our data.

Living in a spacious dwelling or a child-friendly environment is an important motive for leaving the city for families with children and for couples anticipating having children (Mulder and Hooimeijer 1999; Kim et al. 2005; cf. Kulu and Milewski 2007). The evidence concerning the association between the occurrence of childbirth and migration is mixed. In some studies, no effect (Clark and Huang 2003; Clark and Ledwith 2006) or even a negative effect ( $\mathrm{Li}$ 2004) was found. Clark and Huang (2003) found childbirth to have an impact on moving in a longitudinal analysis but not in a cross-sectional analysis. Michielin and Mulder (2008) found that short-distance moves were frequent during pregnancy. Taking a closer look at the effects of conception and birth on residential mobility and migration, Kulu (2008) found that moves from large cities to rural areas are more likely a few months before and after the birth of the first, the second, and even the third child. Interestingly, the second and third births in most cases reduce the likelihood of moving except for leaving large cities for rural destinations (Kulu 2008). Because in our analysis we focus on leaving larger cities, we expect that births trigger migration decisions.

Life-course events bring about changes in life domains. In turn, these changes may lead to changes in the need for particular opportunities and therefore to perceived opportunity differentials that can be expected to be relevant for the process of migration decisionmaking. We consider perceived opportunities with regard to career or income, partnership, family life, and personal interests. Personal interests might be particularly important for young adults, because gaining independence from the parents and living one's own life are important motives for leaving the parental home (Da Vanzo and Kobrin 1982; Monsutti 2007).

There are many other factors known to influence migration that we also need to take into account. It is a stable finding in migration research that highly educated persons are more likely to migrate (cf. Massey et al. 1998; Boyle et al. 1998). Accordingly we expect young adults with a university degree to be more mobile than those with a lower level of education. Ties at the place of residence are constraints for migration, while the migration of friends or relatives has been found to enhance the risk for moving (cf. Massey et al. 1998; Boyle et al. 1998). Therefore, we expect the presence of family members nearby to hamper and the migration of friends or relatives to enhance the likelihood of a migration decision. Furthermore, the partner's wish or necessity to move has a great impact on the migration of couples, especially if it is the wish of the-mostly male-breadwinner (Mincer 1978; Bielby and Bielby 1992; cf. Halfacree 1995). And, finally, previous migration experience strongly increases the likelihood of subsequent migration (cf. Massey et al. 1998; Boyle et al. 1998). One explanation for this finding is that persons who have lived in other towns are more aware of real alternatives (Speare et al. 1975). Persons with migration experience might furthermore have learned to manage realizing a move, to make new friends etcetera, so that they feel more confident and therefore anticipate fewer psychological costs of migration (Massey and Espinosa 1997).

Realizing a move conditional on a moving intention has been found to be particularly influenced by income (Moore 1986; Lu 1998, 1999; Fang 2006). Clark and Ledwith (2006) found a positive effect of income on planning migration. Early adulthood, however, is a life-course phase in which financial resources are often scarce and the standard of living is relatively low, so whether someone has an own income might be more important than the amount of income. A positive impact of having an own income on leaving the parental 
home in the United States was indeed reported for young adults, but the amount of income mattered less (Mulder and Clark 2000).

In summary our expectations about life-course influences on migration decision-making of young adults living in Magdeburg or Freiburg are as follows. We expect decisions in favor of migration to be triggered or enhanced by:

- Starting a tertiary education or starting a job,

- Marriage or starting to live with a partner,

- Childbirth,

- Having experienced the out-migration of family members or close friends,

- Having own migration experience,

- Having a partner who has the wish or necessity to move.

We expect the following characteristics or circumstances to diminish the probability of deciding in favor of migration:

- Having a relatively low level of education,

- Having family ties in town.

The last stage of the migration process, realizing the move, is expected to be facilitated by:

- Having an own income.

\section{Data, variables, and method}

\subsection{Data}

The data were gathered in two German cities, Magdeburg and Freiburg, by carrying out computer-assisted telephone interviews. The field period of the main survey was from April to July 2006. This survey is denoted the first wave. In this first wave, there were three different strata in the sample. First, the respondents were asked how long they already lived in town. Those who moved to the city in the last 12 months were not asked further questions about migration intentions and are therefore not in our selection of respondents. Those who had lived in the city for at least 12 months were asked whether they had recently considered moving. Within this category of respondents, two different strata were formed by over-sampling respondents who had recently considered moving away. These respondents were asked whether they were also planning to do so. After the first wave, the respondents were contacted for follow-up every 4 months. If a respondent had moved away, a second interview (the 'mover-interview') was carried out and the respondent was no longer contacted. Those respondents who had not (yet) moved 1 year after the first wave were interviewed again at that time, from April to July 2007. For convenience we will denote the information gathered in the second interview as the 'second wave', regardless of whether an interview took place 4, 8, or 12 months after the main interview. Respondents who did not move out of town within this year are denoted as 'stayers and those who moved away as 'movers'.

We selected respondents aged 18-29 to represent those in the phase of early adulthood ( $N=1044$ in the first wave). Using weighted data to correct for the over-sampling of respondents who considered moving away, we find that $53.8 \%(n=398)$ of the respondents in early adulthood neither considered nor planned moving away in the first wave, 
$29.5 \%(n=413)$ considered but did not plan moving away, and 16.7\% $(n=233)$ planned moving away. The proportions of considerers and planners are quite high, mainly for two reasons. Firstly, the data were gathered in two cities that have a relatively high migration outflow. Secondly, early adulthood is the phase in the life course in which the proportions of movers are greatest (e.g. Wagner 1989; Mulder 1993).

Follow-up failed for 340 respondents, so there are 704 respondents in the second wave. Panel attrition was least among those who did not consider moving away, medium among those who considered, and highest amongst those who planned to move away. So, movers are probably under-represented among the respondents interviewed in the second wave and stayers are over-represented. Compared to a reference study with a quite similar design, in which face-to-face interviews were conducted (Kalter 1997), the differences between the categories are not that great. Nevertheless we have to take this feature of the data into account in designing the analysis (see Sect. 3.3).

For the analysis we pooled the data for both cities. Apart from different economic conditions due to their location in Eastern (Magdeburg) versus Western Germany (Freiburg) the two cities are quite similar. They both have about 200,000 inhabitants, both have universities, and both are not near another important city within reasonable commuting distance. Table 1 shows how the perceptions of local opportunities are distributed in each of the two cities and how these perceptions are associated with considering and planning to leave the city. The less favorable economic conditions in Magdeburg lead more people in that city to perceive opportunities as better elsewhere than people in Freiburg do (see Table 1, last column). Specifically, $68.1 \%$ of the young adults living in Magdeburg perceive their chances for a career or for having a good income to be better elsewhere than in their home town, but only $48.6 \%$ of the young adults living in Freiburg think in the same

Table 1 Perception of own opportunities better elsewhere among citizens of Magdeburg and Freiburg and percentage considering or planning to leave the city (age 18-29; weighted estimates)

\begin{tabular}{lclll}
\hline & $\begin{array}{l}\text { Neither considering } \\
\text { nor planning } \\
\text { Row percentage }\end{array}$ & $\begin{array}{l}\text { Considering to } \\
\text { leave the city } \\
\text { Row percentage }\end{array}$ & $\begin{array}{l}\text { Planning to } \\
\text { leave the city } \\
\text { Row percentage }\end{array}$ & Total \\
\hline Magdeburg & & & & \\
Career, income & 45.5 & 34.7 & 19.9 & $\mathbf{6 8 . 1}$ \\
Partnership (single) & 28.8 & 41.7 & 29.5 & $\mathbf{8 . 7}$ \\
Partnership (not single) & 31.5 & 38.2 & 30.3 & 11.4 \\
Family & 24.0 & 46.3 & 29.7 & $\mathbf{1 2 . 7}$ \\
Interests & 28.9 & 40.5 & 30.6 & $\mathbf{1 8 . 2}$ \\
Total (row percentage) & 51.7 & 31.7 & 16.5 & 100 \\
Total $(N)$ & 187 & 211 & 110 & 508 \\
Freiburg & & & & $\mathbf{4 0}$ \\
Career, income & 41.2 & 33.5 & 25.3 & $\mathbf{4 8 . 6}$ \\
Partnership (single) & 23.6 & 40.9 & 26.5 & $\mathbf{5 . 7}$ \\
Partnership (not single) & 29.0 & 35.5 & 35.5 & 10.0 \\
Family & 37.4 & 31.3 & 31.3 & $\mathbf{9 . 2}$ \\
Interests & 42.6 & 32.0 & 25.4 & $\mathbf{1 2 . 4}$ \\
Total (row percentage) & 55.6 & 27.6 & 16.8 & 100 \\
Total $(N)$ & 211 & 202 & 123 & 536 \\
\hline Charact & & & & \\
\hline
\end{tabular}

Characters in bold: differences between cities significant with $p \leq 0.05$ 
way. As one might expect, there are significant differences in the percentages between the two cities; these differences run in the same direction and are found in all areas of life, except for perceptions with regard to an existing partnership. This is reasonable because the possibility to maintain an existing partnership hardly depends on the local opportunity structure. Furthermore, Table 1 indicates a relationship between perceiving opportunities as better elsewhere and considering respectively planning to leave the city. For example, $51.7 \%$ of all the young respondents living in Magdeburg neither consider nor plan leaving the city. But among those who perceive the opportunities to follow their own interests as better elsewhere, only $28.9 \%$ neither consider nor plan leaving the city. Compared to the total percentage, the percentage considering migration in this subgroup is about one-third higher, and the percentage planning to leave the city is about doubled. Given the perception of own opportunities as better elsewhere, there are no significant differences in the extent to which citizens of Magdeburg and Freiburg are considering or planning to leave the city.

\subsection{Variables}

Whether people consider or plan leaving the city was measured using the following questions (translated from German): "Have you recently thought about moving away from Magdeburg/Freiburg to live somewhere else?", and, for those who answered affirmatively to this question, "Do you plan to move away from Magdeburg/Freiburg within the next 12 months?" The responses, and the information used for the independent variables, were all gathered in the first wave. The information about whether a respondent stayed or moved within a year after the first interview comes from the follow-up. Movers are respondents who left the city within 1 year after the first interview, stayers are those who did not. Part of the stayers is a small group of respondents who changed residence within town $(5.6 \%$ of the stayers, which equals $4.9 \%$ of all respondents reached in the second wave).

The measurement of the following predictors might not be self-explanatory:

(1) Among the variables measuring demographic and household characteristics, enrolment and level of education is a combined variable with three possible outcomes: "In school or tertiary education" comprises all young people who are currently enrolled in a branch of the educational system, for instance those in college, at university, or in vocational training. "School and at least some training completed" represents the lower and middle level of education. "Studies completed" represents all highly educated respondents with a college or university degree. The question about income refers to the personal monthly income from work or public assistance benefits, after deductions. If the respondents did not answer the open question, they were asked to assign themselves to an income scale in steps of 500 Euros. We distinguish between respondents without an own income or an income below 500 Euros, on the one hand, and respondents with an income of at least 500 Euros, on the other. Seven percent of the investigated group did not report on their income. In order not to lose these cases, a dummy variable for income missing is included in the analyses but not reported in the tables. Living together with a partner includes married and cohabiting couples.

(2) Of the variables measuring ties, previous migration experience was measured as whether a person had lived in different towns or not. Migration of friends or relatives was measured within a 1-year range. The respondents were asked whether friends or relatives had left town during the last 6 months or whether they expected them to do so within the following 6 months. This question only applies to friends or relatives 
with whom the respondent did not live together. The partner's wish or necessity to leave the city is also included, regardless of whether this partner lived in the same household.

(3) The anticipation of life-course events was measured as the expectation that the event would take place within the following 6 months. Tertiary education includes both vocational training and studies at a college or university. Anticipating abandoning one's job was only measured among persons who did not report expecting to start a new job.

(4) Perceiving better opportunities elsewhere than at the place of residence was asked with regard to career prospects and income; maintaining one's partnership or, for those without a partner, finding a partner; family life; and pursuing own interests. We distinguished the measurement of the perception of local opportunities for partnership between persons without a partner and with a partner, because we think this perception means something different to these subgroups of respondents. An effect for singles can be ascribed to the local 'partner market', whereas an effect for persons in a relationship pertains to opportunities to live with that partner or possibly to form a family. A downside of this distinction is that it might cause over-specification, because the measurement of opportunities for a partnership overlaps with the measurement of the presence of a partner. We checked for possible over-specification and did not find any, neither technically (the overlap was not complete) nor substantially (the effects of having a partner remained similar with a different specification).

All variables were dummy-coded except for age, which was measured in years and centered at its mean before forming the age-squared term.

\subsection{Method}

Considering and planning migration was analyzed via generalized ordered logistic regression (Williams 2006). This method is suitable for ordinal dependent variables and therefore meets the assumption that migration decision-making is a process, in that considering migration follows not considering it, and planning follows considering the move. The main advantage of generalized ordered logistic regression over ordinal logistic regression is that one does not have to make the assumption that the influence of a predictor is the same for each stage (proportional-odds or parallel-lines assumption). This relaxation of the proportional-odds assumption is important, because we want to test the hypothesis that the influence of life-course events may be greater on planning than on considering migration. We estimate the likelihood of considering or planning leaving the city versus not considering leaving, and the likelihood of planning to leave the city versus considering or not considering leaving. We used the generalized ordered logistic regression tool written for STATA (Williams 2006). This tool offers a routine that uses an iterative process to identify the partial proportional-odds model that best fits the data. In this process the proportional-odds assumption is tested for each variable. This routine has been used to report for which predictors the proportional-odds assumption has to be rejected with a significance level of 5\%. In order to keep the model as simple as possible, the proportionalodds restriction was only relaxed if the effect of the predictors was significantly different in the planning stage compared with the considering stage.

The realization of the move was analyzed via a binomial logistic regression model of moving versus staying, including all respondents reached in the second wave, while 
considering and planning moving in the first wave were included as predictors. By using the same predictors as for estimating considering and planning the move it is shown which predictors are relevant in this last phase of the migration process. We expect perceived opportunities and life-course events to lose their significance for realizing the move while monetary, social, and psychological resources are expected to be particularly relevant in this stage.

Because panel attrition between the two waves was relatively high, our results are possibly biased. To check for a potential bias, we additionally estimated a probit model with sample selection for the missing cases in the second wave (cf. Van de Ven and Van Praag 1981). Unfortunately, the data contain only a few variables which might exclusively influence panel attrition but are not expected to affect moving. As an additional variable beyond those in the outcome equation, the selection equation includes "having a full-time job", which is known to be associated with being less likely to respond to surveys. The results are reported in the "Appendix". According to the model, the null hypothesis is confirmed that the residuals of the outcome equation and the selection equation are independent of each other. This indicates there is no serious selection problem. The results of this model compared with the results of the binomial logistic regression in Table 4 reflect this, too. Overall, the results of the two models are very similar, but the coefficients are about twice as great in the logistic regression model in Table 4 than in the probit model in the "Appendix". This difference is usually found between logit and probit models.

To correct for the stratification of the sample, frequency weights were applied in the descriptive statistics (Tables 1,2) and probability weights were applied in the logistic regression models (Tables 3,4). Although correcting for sample selection bias is not necessary to track down causal effects in a well specified model, it is recommended when sampling weights are a function of the dependent variable (Winship and Radbill 1994). This is the case in the first model (Table 3), where not considering, considering, and planning to move are the outcome variables, and respondents considering or planning a move have been over-sampled. As Winship and Radbill (1994) show, in these situations correction for sample selection bias via weighting provides consistent estimates of the true regression slopes. That weighting induces heteroskedasticity in the error terms is taken into account by our statistical program, which provides heteroskedastic consistent (robust) standard errors. In Table 4, realizing the move is the outcome variable, and the items of stratification, considering, and planning the move are included as predictors. In that case weighting is usually not necessary and not recommended because of a loss in efficiency of the parameters (Hosmer and Lemeshow 1989; Winship and Radbill 1994). But, owing to the unequal distribution of missing cases over categories of respondents in the second wave, we have reason to assume that in this model, too, the weights are a function of the dependent variable. The selective panel attrition among those who considered or planned moving most likely yields an under-representation of actual movers. For this reason, we also applied sampling weights in the second model; we report robust standard errors.

\section{Results}

4.1 Distribution of respondents' characteristics, evaluations, and expectations

Table 2 shows the distribution of the independent variables in the sample (see last column). For example, more than half of the respondents are currently enrolled in education. Less than half $(40.7 \%)$ of the young adults do not have a partner. Among those who do have a 
Table 2 Descriptive statistics of independent variables measured in the first wave (age 18-29; weighted estimates)

\begin{tabular}{|c|c|c|c|}
\hline $\begin{array}{l}\text { Neither considering } \\
\text { nor planning }\end{array}$ & $\begin{array}{l}\text { Considering to } \\
\text { leave the city }\end{array}$ & $\begin{array}{l}\text { Planning to } \\
\text { leave the city }\end{array}$ & Total \\
\hline Row percentage & Row percentage & Row percentage & $\begin{array}{l}\text { Percentage } \\
\text { in sample }\end{array}$ \\
\hline
\end{tabular}

Socio-demographic variables

Place of residence

Magdeburg

Freiburg

Sex

Female

Male

Age (mean)

Household

Parental household

Own household

Children

Has child(ren)

Has no children

Degree of education

In school or tertiary education

School and some training completed

Studies completed

Income (in Euros)

Less than 500

At least 500

Missing

Partner

Partner lives in household

Partner lives separately

No Partner

Ties and migration experience

Partner wants/has to move

All/most relatives in town

Migration of friends/relatives

Own migration experience

Anticipated life-course events

Completing school

Beginning tertiary education

Completing tertiary education

Abandoning a job

Beginning a job
51.7

55.6

51.5

56.4

24.0

50.3

54.9

68.8

52.1

50.8

63.6

49.3

46.2

56.1

59.1

47.5

53.1

37.2

52.6

36.9

40.2

35.1

38.5

35.9
31.7

27.6

29.6

29.4

23.7

33.0

28.5

24.4

30.1

30.8

27.0

28.4

33.1

28.5

26.6

27.0

30.9

30.0

34.9

26.3

32.1

28.8

36.2

28.9

24.2

34.5

26.5
16.5

46.7

16.8

18.9

53.1

14.2

46.9

23.9

23.8

23.1

16.7

76.9

16.7

10.4

6.8

89.6

17.8

25.6

66.9

15.4

26.2

33.1

40.7

16.9

25.4

20.5

10.9

26.2

30.7

25.9

18.6

73.8

7.0

4.8

30.9

10.6

13.4

40.7

4.5

27.0

18.8 
Table 2 continued

\begin{tabular}{llllr}
\hline & $\begin{array}{l}\text { Neither considering } \\
\text { nor planning } \\
\text { Row percentage }\end{array}$ & $\begin{array}{l}\text { Considering to } \\
\text { leave the city } \\
\text { Row percentage }\end{array}$ & $\begin{array}{l}\text { Planning to } \\
\text { leave the city } \\
\text { Row percentage }\end{array}$ & $\begin{array}{l}\text { Total } \\
\text { Percentage } \\
\text { in sample }\end{array}$ \\
\hline Starting to live with a partner & 45.2 & 21.9 & 32.8 & 7.2 \\
Marriage & 59.4 & 31.9 & 8.7 & 2.5 \\
Birth of a child & 60.4 & 23.9 & 15.7 & 1.8 \\
Total (row percentage) & 53.8 & 29.5 & 16.7 & 100 \\
Total $(N)$ & 398 & 413 & 233 & 1044 \\
\hline
\end{tabular}

partner, more than half live in separate households. Among the anticipated life-course events, divorce is not considered further, due to the very small number of respondents anticipating a divorce.

Table 2 also shows the distribution of the dependent variable of the first analysis (neither considering nor planning migration; considering migration; planning it) over the categories of the independent variables. Altogether, the distribution of those not considering moving, those considering moving, and those planning moving according to the socio-demographic variables and variables referring to ties to the current location is as expected. For example, planning to leave the city is more frequent among highly educated people who completed college or university. Among respondents who live together with a partner considering or planning to leave the city is rather rare, whereas respondents whose partners wish to move often consider or plan moving. Planning to migrate is rather frequent among those anticipating certain life-course events in the following 6 months, like beginning or completing tertiary education. So, a first glance at the descriptive statistics confirms our expectations.

There are no significant differences between the inhabitants of the two cities with respect to the relationship between the independent and the dependent variables, with one exception (not shown in table).The exception is that young adults in Magdeburg who have completed school and reached a low or middle educational standard-we might call them the less well educated-consider or plan leaving the city more frequently than those living in Freiburg. This can traced back to the fact that the labor market in Magdeburg is less favorable for young adults than in Freiburg. For example, among the less well or middle educated respondents living in Magdeburg, 20.7\% are unemployed whereas $13.9 \%$ of their counterparts living in Freiburg are unemployed. Accordingly, 67.6\% of the less well educated young adults living in Magdeburg perceive opportunities for career or income as better elsewhere than in their hometown, compared to $34.2 \%$ of those living in Freiburg.

\subsection{Considering and planning to leave the city}

All anticipated life-course events except for marriage and having a child are relevant for migration decision-making in our sample. Completing school, beginning or completing tertiary education, abandoning or beginning a job all significantly increase the likelihood of considering or planning leaving the city (see Table 3 ). If the young adult has a partner who lives in a separate household, the expectation of starting to live with the partner deters the young adult from leaving the city, contrary to our expectations. Obviously in most cases the formation of a joint household in the city of residence of the respondent is planned. 
Table 3 Generalized ordered logistic regression of considering and planning to leave the city in early adulthood (age 18-29; weighted estimates)

Coeff.

Beta: not considering $\rightarrow$ considering

Socio-demographic variables

Lives in Freiburg (reference: Magdeburg)

Female

Age

Age squared

Lives in parental household

Has child(ren)

Degree of education: (reference: In school or tertiary education)

School and at least some training completed

School and at least some training completed $\times$ lives in Freiburg

Studies completed

Income at least $500 €$ (ref.: less than $500 €)^{\mathrm{a}}$

Partner: (reference: no partner)

Partner lives in household

Partner lives separately

Ties and migration experience

Partner wants/has to move

All/most relatives in town

Migration of friends or relatives

Own migration experience

Anticipated life-course events

Completing school

Beginning tertiary education

Completing tertiary education

Abandoning a job

Beginning a job

Starting to live with a partner

Marriage

Birth of a child

Perception of own opportunities better elsewhere

Career, income

Partnership, single

Partnership, not single

Family life

Pursue own interests

Constant

Gamma: considering $\rightarrow$ planning $^{\mathrm{b}}$

Own migration experience

Beginning tertiary education

Beginning a job

Starting to live with a partner
Robust SE

$\begin{array}{cc}0.00 & 0.16 \\ 0.33^{* *} & 0.14 \\ -0.01 & 0.01 \\ -0.00 & 0.01 \\ 0.08 & 0.24 \\ -0.38 & 0.27 \\ & \\ 0.12 & 0.23 \\ -0.59^{*} & 0.32 \\ 0.44^{*} & 0.24 \\ -0.46^{* *} & 0.19 \\ & \\ -0.55^{* * *} & 0.21 \\ -0.03 & 0.19\end{array}$

$\begin{array}{ll}0.67 * * * & 0.18 \\ -0.48 \text { *** } & 0.17 \\ 0.89 * * * & 0.16 \\ 0.13 & 0.19\end{array}$

$\begin{array}{ll}0.81 * * * & 0.31 \\ 0.56 * * & 0.26 \\ 0.63 * * * & 0.23 \\ 0.65 * * & 0.29 \\ 0.72 * * * & 0.21 \\ -0.78 * * & 0.32 \\ 0.07 & 0.46 \\ -0.21 & 0.62\end{array}$

$0.74 * * *$

0.15

$0.82 * * *$

0.25

$0.59 * *$

0.25

$0.72 * * *$

0.22

$0.71 * * *$

0.17

$-0.95$

0.76

$0.61 * * *$

$0.98 * * *$

0.23

$0.71 * * *$

0.20

$0.62 * *$

0.25 
Table 3 continued

\begin{tabular}{lcc}
\hline & Coeff. & Robust SE \\
\hline Constant & $-3.73^{* * * *}$ & 0.77 \\
Number of cases & 1044 & \\
Wald $\mathrm{Chi}^{2}$ (degrees of freedom) & $308.4(34)$ & \\
Model significance & 0.000 & \\
McFadden's $R^{2}$ & 0.18 & \\
\hline
\end{tabular}

${ }^{a}$ Respondents who did not report on their income considered but coefficient not displayed

b Betas are the parameters for the first stage: considering or planning versus not considering. Gammas are deviations from proportionality to betas for the second stage: planning versus not considering or considering. Parameters for which the proportional-odds assumption is not rejected at $p<0.05$ are constrained to be the same as betas (that is, gamma $=0$ ) and therefore not displayed separately

$* p<0.10, * * p<0.05, * * * p<0.01$

This is in line with the finding that long-distance moves are unlikely if young adults leave the parental home for union formation (Wagner 1989; Mulder 1993; Kley and Huinink 2006).

For most anticipated life-course events, the null hypothesis that the effect on the considering stage of the decision process (considering or planning versus not considering migration) has the same size and magnitude as the effect on the planning stage (planning versus not considering or considering) is not rejected. There are three life-course events, however, that have a significantly greater effect on planning than on considering a move: beginning tertiary education, beginning a job, and starting to live with a partner. All these events have the characteristics of building new ties to a residential location. Beginning tertiary education and beginning a job are regularly interlinked with local opportunities. Therefore these findings support our argumentation: only those who consider moving will keep an eye on opportunities outside their hometown. The arrival and acceptance of such an opportunity then triggers the transition into the planning stage. Starting to live with a partner decreases the likelihood of considering leaving the city. But the results show that young adults who consider a move in connection with union formation are not significantly less likely to plan a move than those without this event (the gamma parameter of 0.62 for the planning stage almost offsets the beta parameter of -0.78 for the considering stage; the resulting coefficient of -0.16 for the planning stage is not significantly different from zero).

Marriage and the expectation to have a child have no effect on considering or planning to leave the city in this age group. But already having a child does not significantly deter young adults from moving either.

Perceiving a lack of opportunities at the place of residence is strongly associated with considering and planning migration (see Table 3). All coefficients of the variables measuring the perception that opportunities in different spheres of life are better elsewhere are positive and significant. Possibilities for career and income, for finding a partner if single, for having a good family life, and for pursuing own interests are equally important to migration decisions. Slightly less relevant are considerations about the opportunities for an existing partnership.

Socio-demographic variables also influence migration decision-making. Most of their effects are in line with our expectations: females in this age group are more likely to consider and plan moving, and the same is true for highly educated persons. There is an interaction effect for young adults who completed school and at least some training-we 
might call them the less well or middle educated-with the city of residence. Less educated young adults living in Freiburg are estimated to have a lower chance of considering or planning a move than those living in Magdeburg. This can be interpreted as an expression of the economic differences between the two cities. As mentioned above, in Magdeburg a significantly higher percentage of less well or middle educated young adults are unemployed, and correspondingly a much higher percentage of them perceive the opportunities for a career as better elsewhere. Taking this interaction into account, living in Freiburg does not have a negative effect on considering or planning to leave the city. This is shown in the first line of Table 3, which depicts the effect of living in Freiburg for highly educated young adults and those still enrolled in education.

Respondents who live with a partner are less likely to opt for moving than singles, whereas having a partner who lives separately does not deter young adults from deciding to leave the city. Unexpectedly, having an income of at least 500 Euros deters young adults from considering and planning a move. These young adults are mostly not living with their parents and are mostly working.

Having all or most relatives in town deters young people from considering and planning to leave the city. Other local ties are highly relevant for migration decision-making as well. The partner's wish to move significantly enhances the respondent's likelihood of considering or planning a move. The same is true for the experience of friends or relatives leaving town. Own migration experience particularly enhances planning migration. This is in line with the learning hypothesis (Massey and Espinosa 1997): own moving experience enhances skills and knowledge about managing a move, and it probably enhances the selfconfidence that living in another town and making new friends is feasible.

\subsection{Realizing the move}

For realizing the move, resources were expected to be relevant, whereas anticipated lifecourse events and perceived opportunities were not expected to have an additional influence on this last stage of the migration process. Furthermore, the previous phases of the migration process, especially planning a move, were expected to have positive effects on actually leaving the city. These expectations are supported by the results (see Table 4; cf. Table 5 in the "Appendix"). Considering and planning moving away are both strong predictors of realizing a move. Having planned a move increases the likelihood of actually moving to the highest degree among all predictors while the effect of having considered it is smaller but also significant.

Resources are highly relevant for realizing a move across the city boundaries, as expected. For young adults with an own income of at least 500 Euros, the odds of realizing a move are significantly greater than for those without or with less income. Further analysis (results not shown) reveals that this effect only applies to those who are no longer living in the parental household. For young persons who live with their parents, having an own income of at least 500 Euros does not significantly affect realizing the move.

Living in the parental household in itself increases the odds of moving significantly. This result is in line with the fact that many young persons leave the parental home for enrolment at a university elsewhere, before starting to earn an income. Because planning a move for educational or other reasons is considered in the estimation, this finding could also be interpreted as an indicator of having social capital that might compensate a lack of own financial capital. As Mulder and Clark (2000) have shown for the United States, parental income particularly enhances the likelihood that young adults leave home to live 
Table 4 Binomial Logistic regression of realizing versus not realizing leaving the city in early adulthood (age 18-29; weighted estimates)

\begin{tabular}{|c|c|c|}
\hline & Staying $\rightarrow n$ & \\
\hline & Coeff. & Robust SE \\
\hline Migration decision & & \\
\hline Considered moving & $0.79 *$ & 0.44 \\
\hline Planned to move & $2.85^{* * * *}$ & 0.35 \\
\hline Socio-demographic variables & & \\
\hline Lives in Freiburg (ref. Magdeburg) & 0.02 & 0.31 \\
\hline Female & 0.14 & 0.29 \\
\hline Age & 0.03 & 0.06 \\
\hline Age squared & -0.02 & 0.02 \\
\hline Lives in parental household & $1.52^{* * * *}$ & 0.47 \\
\hline Has child(ren) & -0.33 & 0.66 \\
\hline Degree of education: (ref. School and at least & ompleted) & \\
\hline In school or tertiary education & 0.30 & 0.46 \\
\hline Studies completed & -0.38 & 0.54 \\
\hline Income at least $500 €(\text { ref.: less than } 500 €)^{\mathrm{a}}$ & $1.23 * * *$ & 0.35 \\
\hline Partner: (reference: no partner) & & \\
\hline Partner lives in household & -0.06 & 0.47 \\
\hline Partner lives separately & -0.14 & 0.38 \\
\hline Ties and migration experience & & \\
\hline Partner wants/has to move & 0.24 & 0.36 \\
\hline All/most relatives in town & 0.21 & 0.36 \\
\hline Migration of friends or relatives & $0.95 * * *$ & 0.34 \\
\hline Own migration experience & $0.88 * *$ & 0.42 \\
\hline Anticipated life-course events & & \\
\hline Events creating new ties ${ }^{\mathrm{b}}$ & 0.37 & 0.29 \\
\hline Other events ${ }^{\mathrm{c}}$ & 0.21 & 0.33 \\
\hline Perception of own opportunities better elsewhe & & \\
\hline At least one ${ }^{\mathrm{d}}$ & 0.51 & 0.47 \\
\hline Constant & $-7.21 * * *$ & 1.45 \\
\hline Number of cases & 704 & \\
\hline Wald $\mathrm{Chi}^{2}$ (degrees of freedom) & $186.5(21)$ & \\
\hline McFadden's $R^{2}$ (degrees of freedom) & $0.41(21)$ & \\
\hline Model significance & 0.000 & \\
\hline
\end{tabular}

\footnotetext{
${ }^{a}$ Respondents who did not report on their income considered separately but coefficient not displayed

b Beginning tertiary education, beginning a job, or starting to live with a partner

${ }^{c}$ Completing school, completing tertiary education, abandoning a job, marriage, or birth of a child

${ }^{\mathrm{d}}$ Career/income, partnership, family life, or pursuing own interests

$* p<0.10 ; * * p<0.05 ; * * * p<0.01$
}

without a partner at a long distance from their parents. Furthermore, there is evidence that unfavorable opportunities for leaving home are often compensated by family support (Mandic 2008). 
The migration of friends and relatives also has a positive effect on realizing a move. This is in line with the results from previous research into the impact of migration networks (Moore 1986; Massey and Espinosa 1997; Lu 1998, 1999; Palloni et al. 2001; Fang 2006). Our results show that information or assistance from others not only fosters the decision to move but is helpful for putting migration plans into action.

Own migration experience enhances the likelihood for realizing the move, too. This finding might be interpreted as a learning effect: former experience of relocation may enhance skills and knowledge about how to manage a move practically (Massey and Espinosa 1997).

As expected, none of the life-course events has a significant effect on realizing a move. The same is true for perceived opportunity differentials between the previous place of residence and the destination. For reasons of the stability of the model these predictors have been combined.

Recalling the differences in perceived opportunities between young adults living in Magdeburg and Freiburg one last result might be pointed out. Once the decision to migrate is taken into account, young adults are equally likely to leave either of both cities. The level of education does not play a role in putting plans into action. Compared to persons with a lower or middle level of education, those with a university degree are not significantly more or less likely to realize migration plans.

\section{Conclusion}

In this paper we have analyzed migration from the city of young adults as a process starting with considering and planning the move and ending in realizing it. Following findings from psychological research on the process of decision-making, we argued that considering a move is an early stage, while planning a move is an indicator that the decision has fallen in favor of moving. Realizing the move was conceptualized as the likely outcome of attempts to put the decision in favor of migration into action.

The results show that migration decision-making is mainly driven by life-course events and by perceived opportunities in several life domains. Particularly at the time of transitions from school to tertiary education and from tertiary education to the labor market, young adults are likely to consider or plan moving. Union formation in the form of marriage or cohabitation and the birth of a child were found to have no effect or even a negative effect on migration decision-making in most cases. Corresponding with the importance of perceived opportunity differentials for partnership and family life, moving intentions of the partner and of friends and relatives are other factors that strongly influence considering and planning migration among young adults.

By analyzing migration decision-making as a process consisting of a stage of considering and a stage of planning the move, it was shown that some anticipated life-course events are particularly important in triggering the decision in favor of migration - the "crossing of the Rubicon'-rather than just enhancing considering migration. The strongest predictors of planning migration in early adulthood are the anticipation of beginning tertiary education and beginning a job. These events have a significantly greater influence on planning than on considering migration. We have argued that only those who consider migration will keep an eye on opportunities outside the city. The arrival and acceptance of such an opportunity then triggers the decision in favor of a move because those events create new social ties at the destination.

Realizing a move could be explained as a result of the earlier phases of considering and planning migration, while resources, migration experience, and social ties were found to have additional effects on actually moving. 
Although important theoretical work on migration suggest distinguishing three stages in the migration process, very few empirical studies have thus far applied three-stage models. With this contribution to the migration literature, we hope to have shown that the distinction of stages is especially useful for the empirical research into the influence of life-course events on migration.

The estimates of the selection equation indicate that the likelihood of participation in the second wave of the survey is enhanced by living in the parental household, being enrolled in school or tertiary education, having a high level of education, and having own migration experience. Respondents who considered moving in the first wave are less likely to participate in the second wave, but this is not the case for those who planned moving. Interestingly, those with a full-time job are more likely to participate in the second wave compared to others. Overall, the estimates indicate that highly educated and relatively well-off persons were more likely to participate in the second wave, and that the same is true for persons who were interested in the topic of the survey.

Acknowledgments This research was made possible by funding through the German Research Foundation (DFG) and a grant from the German Academic Exchange Service (DAAD). Clara Mulder's contribution was made possible by the Netherlands Organization for Scientific Research (NWO), Innovational Research Incentives Scheme (VICI) grant no. 453-04-001. We would like to thank our colleagues for useful comments on an earlier version of this paper, especially Johannes Huinink and Michael Windzio (both University of Bremen) and Pieter Hooimeijer (University of Utrecht).

Open Access This article is distributed under the terms of the Creative Commons Attribution Noncommercial License which permits any noncommercial use, distribution, and reproduction in any medium, provided the original author(s) and source are credited.

\section{Appendix}

See Table 5.

Table 5 Probit model with sample selection of realizing versus not realizing leaving the city in early adulthood (age 18-29; weighted estimates)

\begin{tabular}{|c|c|c|c|c|}
\hline & \multirow{2}{*}{\multicolumn{2}{|c|}{$\frac{\text { Outcome equation }}{\text { Staying } \rightarrow \text { moving }}$}} & \multirow{2}{*}{\multicolumn{2}{|c|}{$\begin{array}{l}\text { Selection equation } \\
\text { Participated in } 1 . \\
\text { Wave } \rightarrow \text { in } 2 . \text { Wave }\end{array}$}} \\
\hline & & & & \\
\hline & Coeff. & Robust SE & Coeff. & Robust SE \\
\hline \multicolumn{5}{|l|}{ Migration decision } \\
\hline Considered moving & $0.41 * *$ & 0.20 & $-0.17 *$ & 0.10 \\
\hline Planned to move & $1.61 * * *$ & 0.19 & -0.12 & 0.12 \\
\hline \multicolumn{5}{|l|}{ Socio-demographic variables } \\
\hline Lives in Freiburg (ref. Magdeburg) & -0.01 & 0.16 & 0.03 & 0.09 \\
\hline Female & 0.08 & 0.15 & 0.04 & 0.09 \\
\hline Age & 0.02 & 0.03 & 0.02 & 0.02 \\
\hline Age squared & -0.01 & 0.01 & -0.01 & 0.00 \\
\hline Lives in parental household & $0.81 * * *$ & 0.25 & $0.26^{*}$ & 0.15 \\
\hline Has child(ren) & -0.26 & 0.32 & 0.03 & 0.17 \\
\hline
\end{tabular}


Table 5 continued

\begin{tabular}{|c|c|c|c|c|}
\hline & \multirow{2}{*}{\multicolumn{2}{|c|}{$\frac{\text { Outcome equation }}{\text { Staying } \rightarrow \text { moving }}$}} & \multirow{2}{*}{\multicolumn{2}{|c|}{$\begin{array}{l}\text { Selection equation } \\
\text { Participated in } 1 . \\
\text { Wave } \rightarrow \text { in } 2 . \text { Wave }\end{array}$}} \\
\hline & & & & \\
\hline & Coeff. & Robust SE & Coeff. & Robust SE \\
\hline \multicolumn{5}{|c|}{ Degree of education: (ref. School and at least some training completed) } \\
\hline In school or tertiary education & 0.12 & 0.24 & $0.43 * * *$ & 0.14 \\
\hline Studies completed & -0.26 & 0.33 & $0.52 * * *$ & 0.16 \\
\hline Income at least $500 €(\text { ref.: less than } 500 €)^{\mathrm{a}}$ & $0.64 * * *$ & 0.19 & 0.13 & 0.11 \\
\hline \multicolumn{5}{|l|}{ Partner: (reference: no partner) } \\
\hline Partner lives in household & -0.02 & 0.23 & 0.02 & 0.13 \\
\hline Partner lives separately & -0.03 & 0.20 & -0.01 & 0.11 \\
\hline \multicolumn{5}{|l|}{ Ties and migration experience } \\
\hline Partner wants/has to move & 0.05 & 0.19 & -0.02 & 0.12 \\
\hline All/most relatives here & 0.12 & 0.20 & -0.10 & 0.11 \\
\hline Migration of friends or relatives & $0.50 * *$ & 0.19 & -0.10 & 0.12 \\
\hline Own migration experience & $0.43 * *$ & 0.21 & $0.23 * *$ & 0.11 \\
\hline \multicolumn{5}{|l|}{ Anticipated life-course events } \\
\hline Events creating new ties ${ }^{\mathrm{b}}$ & 0.18 & 0.15 & 0.03 & 0.10 \\
\hline Other events ${ }^{c}$ & 0.12 & 0.18 & -0.16 & 0.12 \\
\hline \multicolumn{5}{|l|}{ Perception of own opportunities better elsewhere } \\
\hline At least one ${ }^{\mathrm{d}}$ & 0.25 & 0.22 & -0.03 & 0.11 \\
\hline \multicolumn{5}{|l|}{ Chance of participation in surveys } \\
\hline Having a full-time job & & & $0.44^{* * *}$ & 0.15 \\
\hline Constant & $-3.95 * * *$ & 0.90 & -0.43 & 0.49 \\
\hline Number of cases & 1.044 & & & \\
\hline Censored cases & 340 & & & \\
\hline Wald $\mathrm{Chi}^{2}$ (degrees of freedom) & $209.7(21)$ & & & \\
\hline Model significance & 0.000 & & & \\
\hline $\begin{array}{l}\text { Wald test of indep. epns. (rho }=0): \mathrm{Chi}^{2} \\
\text { (degrees of freedom) }\end{array}$ & $0.00(1)$ & & & \\
\hline Wald test significance & 0.98 & & & \\
\hline
\end{tabular}

\footnotetext{
${ }^{a}$ Respondents who did not report on their income considered separately but coefficient not displayed

b Beginning tertiary education, beginning a job, or starting to live with a partner

c Completing school, completing tertiary education, abandoning a job, marriage, or birth of a child

${ }^{\mathrm{d}}$ Career/income, partnership, family life, or pursuing own interests

$* p<0.10 ; * * p<0.05 ; * * * p<0.01$
}

\section{References}

Andersen, H. S. (2008). Why do residents want to leave deprived neighbourhoods? The importance of residents' subjective evaluations of their neighbourhood and its reputation. Journal of Housing and the Built Environment, 23(2), 79-101.

Bielby, W., \& Bielby, D. (1992). I will follow him: Family ties, gender-role beliefs, and reluctance to relocate for a better job. American Journal of Sociology, 97(5), 1241-1267.

Boyle, P., Halfacree, K., \& Vaughan, R. (1998). Exploring contemporary migration. Harlow: Pearson. 
Brown, L., \& Moore, G. (1970). The intra-urban migration process: A perspective. Geografiska Annaler, $52 B, 1-13$.

Clark, W. A. V., \& Huang, Y. (2003). The life course and residential mobility in British housing markets. Environment and Planning A, 35(2), 323-339.

Clark, W. A. V., \& Ledwith, V. (2006). Mobility, housing stress, and neighborhood contexts: Evidence from Los Angeles. Environment and Planning A, 38, 1077-1093.

Da Vanzo, J., \& Kobrin, E. (1982). Leaving the nest and the transition to adulthood. Santa Monica: The Rand Corporation.

De Groot, C., Manting, D., \& Mulder, C. H. (2007, June). Intentions to move and actual moving behaviour in the Netherlands. Paper presented at the ENHR conference, Rotterdam.

De Jong, G., et al. (1985/86). Migration intentions and behavior: Decision making in a rural Philippine province. Population and Environment, 8(1/2), 41-62.

Duncan, G. J., \& Newman, S. J. (1976). Expected and actual residential mobility. Journal of the American Institute of Planners, 42, 174-186.

Fang, Y. (2006). Residential satisfaction, moving intentions and moving behaviours: A study of redeveloped neighbourhoods in inner-city Beijing. Housing Studies, 21(5), 671-694.

Fuller, T., Lightfoot, P., \& Kamnuansilpa, P. (1985/86). Mobility plans and mobility behavior: Convergences and divergences in Thailand. Population and Environment, 8(1/2), 15-40.

Gardner, R. W., et al. (1985/86). The best-laid schemes: an analysis of discrepancies between migration intentions and behavior. Population and Environment, 8(1/2), 63-77.

Geist, C., \& McManus, P. (2008). Geographical mobility over the life course: motivations and implications. Population. Space and Place, 14(4), 283-303.

Gollwitzer, P. M. (1996). The volitional benefits of planning. In P. M. Gollwitzer (Ed.), The psychology of action: Linking cognition and motivation to behavior (pp. 287-312). New York: Guilford Press.

Halfacree, K. H. (1995). Household migration and the structuration of patiarchy: Evidence from the USA. Progress in Human Geography, 19(2), 159-182.

Heckhausen, H. (1991). Motivation and action. New York: Springer.

Heckhausen, H., \& Gollwitzer, P. M. (1987). Thought contents and cognitive functioning in motivational versus volitional states of mind. Motivation and Emotion, 11(2), 101-120.

Hosmer, D. W., \& Lemeshow, S. (1989). Applied logistic regression. New York: Wiley.

Huinink, J., \& Wagner, M. (1989). Regionale Lebensbedingungen, Migration und Familienbildung. Kölner Zeitschrift für Soziologie und Sozialpsychologie, 41, 669-689.

Kalter, F. (1997). Wohnortwechsel in Deutschland. Ein Beitrag zur Migrationstheorie und zur empirischen Anwendung von Rational-Choice-Modellen. Opladen: Leske+Budrich.

Kan, K. (1999). Expected and unexpected residential mobility. Journal of Urban Economics, 45, 72-96.

Kim, T.-K., Horner, M., \& Marans, R. (2005). Life cycle and environmental factors in selecting residential and job locations. Housing Studies, 20(3), 457-473.

Kley, S., \& Huinink, H. (2006). Die Gründung des eigenen Haushalts bei Ost- und Westdeutschen nach der Wiedervereinigung. Zeitschrift für Bevölkerungswissenschaft, 1, 127-154.

Kulu, H. (2008). Fertility and spatial mobility in the life course: evidence from Austria. Environment and Planning A, 40(3), 632-652.

Kulu, H., \& Milewski, N. (2007). Family change and migration in the life course: An introduction. Demographic Research, 17(19), 567-590.

Landale, N. S., \& Guest, A. M. (1985). Constraints, satisfaction and residential mobility: Speare's model reconsidered. Demography, 22(2), 199-222.

Li, S.-M. (2004). Life course and residential mobility in Beijing, China. Environment and Planning A, 36(1), 24-43.

Lu, M. (1998). Analyzing migration decisionmaking: relationships between residential satisfaction, mobility intentions, and moving behavior. Environment and Planning A, 30, 1473-1495.

Lu, M. (1999). Do people move when they say they will? Inconsistencies in individual migration behavior. Population and Environment, 20(5), 467-487.

Mandic, S. (2008). Home-leaving and its structural determinants in western and eastern Europe: An exploratory study. Housing Studies, 32(4), 615-637.

Massey, D., \& Espinosa, K. (1997). What's driving Mexico-U.S. migration? A theoretical, empirical, and policy analysis. American Journal of Sociology, 102(4), 939-999.

Massey, D., et al. (1998). Worlds in motion. Understanding international migration at the end of the Millenium. Oxford: Clarendon Press.

Mayer, K. U. (2004). Whose lives? How history, societies, and institutions define and shape life courses. Research in Human Development, 1(3), 161-187. 
McHugh, K. E. (1984). Explaining migration intentions and destination selection. Professional Geographer, 36(3), 315-325.

Michielin, F., \& Mulder, C. H. (2008). Family events and the residential mobility of couples. Environment and Planning A, 40, 2770-2790.

Mincer, J. (1978). Family migration decisions. Journal of Political Economy, 86(5), 749-773.

Monsutti, A. (2007). Migration as a rite of passage: Young Afghans building masculinity and adulthood in Iran. Iranian Studies, 40(2), 167-185.

Moore, E. G. (1986). Mobility intention and subsequent relocation. Urban Geography, 7(6), 497-514.

Mulder, C. H. (1993). Migration dynamics: A life course approach. Amsterdam: Thesis Publishers.

Mulder, C. H. (1996). Housing choice: Assumptions and approaches. Journal of Housing and the Built Environment, 11(3), 209-232.

Mulder, C. H., \& Clark, W. A. V. (2000). Leaving home and leaving the state: Evidence from the United States. International Journal of Population Geography, 6, 423-437.

Mulder, C. H., \& Hooimeijer, P. (1999). Residential relocations in the life course. In L. J. G. van Wissen \& P. A. Dykstra (Eds.), Populations Issues. An Interdisciplinary Focus (p. 159). New York: Kluwer Academic/Plenum Publishers.

Mulder, C. H., \& Wagner, M. (1993). Migration and marriage in the life course: a method for studying synchronized events. European Journal of Population, 9, 55-76.

Palloni, A., et al. (2001). Social capital and international migration: A test using information on family networks. American Journal of Sociology, 106(5), 1262-1298.

Rossi, P. H. (1980 [1955]). Why families move. Beverly Hills/London: Sage.

Simmons, A. B. (1985/86). Recent studies on place-utility and intention to migrate: An international comparison. Population and Environment, 8(1/2), 12-140.

Sjaastad, L. A. (1962). The costs and returns of human migration. Journal of Political Economy, 70(5), 80-93.

Sly, D. F., \& Wrigley, J. M. (1985/86). Migration decision making and migration behavior in rural Kenya. Population and Environment, 8(1/2), 78-97.

Speare, A. (1971). A cost-benefit model of rural to urban migration in Taiwan. Population Studies, 25, $117-130$.

Speare, A. (1974). Residential satisfaction as an intervening variable in residential mobility. Demography, 11, 173-188.

Speare, A., Goldstein, S., \& Frey, W. H. (1975). Residential mobility, migration, and metropolitan change. Cambridge: Ballinger.

Van de Ven, W., \& van Praag, B. (1981). The demand for deductibles in private health insurance. Journal of Econometrics, 17, 229-252.

Wagner, M. (1989). Räumliche Mobilität im Lebensverlauf. Eine empirische Untersuchung sozialer Bedingungen der Migration. Stuttgart: Enke.

Williams, R. (2006). Generalized ordered logit / Partial proportional odds models for ordinal dependent variables. The Stata Journal, 6(1), 58-82.

Winship, Ch., \& Radbill, L. (1994). Sampling weights and regression analysis. Sociological Methods and Research, 23(2), 230-257. 